\title{
Gender and Development in Sex Roles
}

\author{
Margaret L. Signorella
}

Published online: 14 August 2012

(C) Springer Science+Business Media, LLC 2012

When Sex Roles marked its 35th anniversary (Frieze and Dittrich 2010), one of the celebratory articles was a content analysis of gender development research published in the journal (Zosuls et al. 2011). The authors of the analysis noted that Sex Roles began at a time when seminal works on the study of gender were appearing and crucial issues in terminology were debated (cf., Frieze and Chrisler 2011). The Zosuls et al. review also clearly showed that Sex Roles has been a consistent outlet for a wide variety of gender development issues, across different ages and methodologies.

One of the strengths of Sex Roles is its encouragement of research from across the globe. Recognizing and wishing to enhance this trend, Frieze and Dittrich announced in 2008 that in order to reflect the vision of Sex Roles as an international journal, henceforth authors were to identify clearly in the abstract and method sections where the samples originated, consider the cultural context of any works cited, and discuss the role of gender within the sample's culture. Evidence of an amplified international impact specifically in the gender development arena can be seen in Zosuls et al.'s Table 2 (2011). Articles they coded as cross-cultural increased from $4 \%$ in the 1970 s to around $10 \%$ in the 1980 s and 1990 s to $17 \%$ in the 2000 s. Three of the articles in the developmental section of this issue are from outside the U.S. (China: Zhou et al. 2012; The Netherlands: Jellesma and Vingerhoets 2012; Spain: Táboas-Pais and Rey-Cao 2012).

The strength of Sex Roles in the use of content analysis, exemplified by the Zosuls et al. (2011) analysis, continues in the current issue. Auster and Mansbach (2012) examined the colors and gender designations of toys sold online at the

M. L. Signorella $(\bowtie)$

Pennsylvania State University, Greater Allegheny,

McKeesport, PA, USA

e-mail: msignorella@psu.edu
English-language Disney Store. In addition to showing the expected relationship between the current stereotyping of colors (e.g., pink for girls, blue for boys) and the stereotyping of the toys (e.g., dolls for girls, truck for boys), the authors also discovered that the toys intended for both boys and girls tended to have the stereotypical masculine color schemes. Táboas-Pais and Rey-Cao (2012) coded images in physical education textbooks from Spain. The photographs more frequently showed male participants, and also showed them in competitive settings and in the outdoors more frequently than female participants. In a noncommercial comparison, Wondergem and Friedlmeier (2012) used yearbook pictures from kindergarten through 12th grade to compare smiling by gender in students from different ethnic backgrounds in the U.S. Their analysis revealed that gender and ethnicity differences in smiling did not become significant until preadolescence.

Adjustment and identity are other areas that have received increased attention in Sex Roles (Zosuls et al. 2011). In this issue, Jellesma and Vingerhoets (2012) surveyed preadolescent children in the Netherlands on crying and its correlates. Although the absolute frequencies of crying reported were quite low, differences were in the expected direction, with girls indicating a greater tendency to cry and more instances of crying. The authors found some support for their hypothesis that mediating the gender differences are internalizing factors. Patterson (2012) surveyed children ages 6-12 from the U.S. and showed that those children who viewed themselves as more typical of their gender not only showed interests that were traditional but also had more traditional gender-related attitudes.

Zosuls et al. (2011) identified areas as needing more investigation. The current issue is responsive to the call for more research on peers, including use of observational methods. Goble et al. (2012) report on observations of U.S. preschoolers playing in different contexts, such as solitary, with peers, and with teachers. During solitary play, 
girls' play was more frequently in feminine and neutral activities, whereas boys' play was more frequently in masculine activities. During play or interactions with others, these patterns shifted. For example, play in mixed-gender groups increased engagement in neutral activities for both boys and girls. The authors suggested that different play contexts might be a way for children to broaden their skills and gain both social and academic benefits. A study with adolescents in China examined gender differences in the moderators of friendship quality, showing that narcissism predicted friendship quality in boys but not girls (Zhou et al. 2012).

Starr and Ferguson (2012) in this issue addressed another area identified by Zosuls et al. (2011) as relatively neglected; namely, the effects on gender development of exposure to various media. Young girls ages 6-9 from the U.S were surveyed on which type of doll they were most like and would most prefer to play with. The forced choice between a doll dressed in a sexualized manner versus a nonsexualized portrayal showed that although the girls chose the sexualized doll as their ideal and as most popular, they preferred the nonsexualized doll as a plaything. Although high media usage did not prediction early sexualization, girls whose mothers reported monitoring and restricting their media consumption were less likely to identify with the sexualized doll.

In 2008 the editor of Sex Roles, Irene Hanson Frieze, invited me to become an associate editor specializing in articles about development. Since that time, I have not only been reviewing gender development articles, but also co-editing with Rebecca S. Bigler a two-part special issue on single-sex education (Signorella and Bigler 2011, 2012). I encourage researchers exploring gender development to consider submitting to Sex Roles, not only to build upon the current strengths of the journal but also to add to underexplored areas. In addition to the areas cited above, Zosuls et al. (2011) suggested that samples below adolescence need more attention, in particular those with very young children, as there are many important theoretical questions about the origin of gender differences that need to be explored in these age groups. Research using multiple measures and analytic methods that assess causal models of gender development would be important contributions to the literature. At all ages and across all methods, the continued exploration of multidimensional aspects of gender development (cf., Signorella 1999) is crucial.

\section{References}

Auster, C. J., \& Mansbach, C. S. (2012). The gender marketing of toys: An analysis of color and type of toy on the Disney Store website. Sex Roles. doi:10.1007/s11199-012-0177-8.

Frieze, I. H., \& Chrisler, J. C. (2011). Editorial policy on the use of the terms "sex" and "gender" [Editorial]. Sex Roles, 64, 789-790. doi:10.1007/s11199-011-9988-2.

Frieze, I. H., \& Dittrich, S. (2008). Sex Roles: An international journal. Sex Roles, 58, 751. doi:10.1007/s11199-008-9433-3.

Frieze, I. H., \& Dittrich, S. (2010). Sex Roles is 35! Sex Roles, 62, 1. doi:10.1007/s11199-009-9720-7.

Goble, P., Martin, C. L., Hanish, L. D., \& Fabes, R. A. (2012). Children's gender-typed activity choices across preschool social contexts. Sex Roles. doi:10.1007/s11199-012-0176-9.

Jellesma, F. C., \& Vingerhoets, A. J. J. M. (2012). Crying in middle childhood: A report on gender differences. Sex Roles. doi:10.1007/s11199-012-0136-4.

Patterson, M. M. (2012). Self-perceived gender typicality, gendertyped attributes, and gender stereotype endorsement in elementary-school-aged children. Sex Roles. doi:10.1007/ s11199-012-0184-9.

Signorella, M. L. (1999). Multidimensionality of gender schemas: Implications for the development of gender-related characteristics. In W. B. Swann Jr., J. H. Langlois, \& L. A. Gilbert (Eds.), Sexism and stereotypes in modern society: The gender science of Janet Taylor Spence (pp. 107-126). Washington, DC: American Psychological Association. doi:10.1037/10277-005.

Signorella, M. L., \& Bigler, R. S. (Eds.) (2011). Single-Sex Schooling Part I [Special issue]. Sex Roles, 65.

Signorella, M. L., \& Bigler, R. S. (Eds.) (2012). Single-Sex Schooling Part II [Special issue]. Special issue in preparation.

Starr, C. R., \& Ferguson, G. M. (2012). Sexy dolls, Sexy gradeschoolers? Media \& maternal influences on young girls' selfsexualization. Sex Roles. doi:10.1007/s11199-012-0183-x.

Táboas-Pais, M. I., \& Rey-Cao, A. (2012). Gender differences in physical education textbooks in Spain: A content analysis of photographs. Sex Roles. doi:10.1007/s11199-012-0174-y.

Wondergem, T. R., \& Friedlmeier, M. (2012). Gender and ethnic differences in smiling: A yearbook photographs analysis from kindergarten through 12th grade. Sex Roles. doi:10.1007/ s11199-012-0158-y.

Zhou, H., Li, Y., Zhang, B., \& Zeng, M. (2012). The relationship between narcissism and friendship qualities in adolescents: Gender as a moderator. Sex Roles. doi:10.1007/s11199-012-0169-8.

Zosuls, K. M., Miller, C. F., Ruble, D. N., Martin, C. L., \& Fabes, R. A. (2011). Gender development research in Sex Roles: Historical trends and future directions. Sex Roles, 64, 826-842. doi:10.1007/s11199-010-9902-3. 